ISSN 0103-9954

\title{
ANATOMIA DA MADEIRA DE DUAS ESPÉCIES DO GÊNERO Heterothalamus Lessing (ASTERACEAE) NATIVAS NO RIO GRANDE DO SUL.
}

WOOD ANATOMY OF TWO SPECIES OF THE GENUS Heterothalamus Lessing (ASTERACEAE) FROM RIO GRANDE DO SUL (BRAZIL)

Anabela Silveira de Oliveira ${ }^{1}$ Leonardo Paz Deble ${ }^{2}$ José Newton Cardoso Marchiori ${ }^{3}$ Luciano Denardi ${ }^{4}$

\section{RESUMO}

O presente trabalho descreve a anatomia da madeira de Heterothalamus alienus e Heterothalamus rupestris (Astereae - Asteraceae), como parte do estudo do xilema secundário do referido gênero. Para ambas as espécies, foram confirmados detalhes anatômicos mencionados na literatura para a família Asteraceae, como vasos tipicamente pequenos e agrupados em padrão dendrítico, placas de perfuração invariavelmente simples e parênquima paratraqueal. Heterothalamus alienus possui espessamentos espiralados nos vasos lenhosos e parênquima axial vasicêntrico estratificado. Heterothalamus rupestris distingue-se pela ausência de espessamentos espiralados nos vasos e pelo parênquima paratraqueal vasicêntrico a unilateral. São fornecidas fotomicrografias, dados quantitativos de características anatômicas e uma comparação entre a madeira das duas espécies.

Palavras-chave: Asteraceae; Heterothalamus alienus; Heterothalamus rupestris; anatomia da madeira.

\section{ABSTRACT}

The present work describes the wood anatomy of Heterothalamus alienus and Heterothalamus rupestris (Astereae - Asteraceae), as part of the secondary xylem study in the named genus. For the two species it was recorded some features usually mentioned in the literature for the Asteraceae, as typically small vessels, grouped in a dendritic pattern, the presence of only simple perforation plates and of paratracheal parenchyma. Heterothalamus alienus shows spiral thickenings in the wood vessels and storied vasicentric axial parenchyma. Heterothalamus rupestris differs itself by the absence of spiral thickenings in wood vessels and by no storied axial parenchyma, in paratracheal vasicentric to unilateral patterns. Photomicrographs, quantitative data of anatomical features and a comparison between the two species of wood are also provided.

Key words: Asteraceae; Heterothalamus alienus; Heterothalamus rupestris; wood anatomy.

\section{INTRODUÇÃO}

A família Compositae ou Asteraceae compreende cerca de 1.100 gêneros e 25 mil espécies, distribuídas nas regiões tropicais, subtropicais e temperadas do mundo, desde o nível do mar até o pico de altas montanhas. No Brasil, ocorrem cerca de 180 gêneros (Barroso, 1991).

O gênero Heterothalamus Lessing, pertencente à subtribo Baccharinae (tribo Astereae), caracterizase por incluir plantas polígamo-dióicas ou imperfeitamente dióicas, de porte subarbustivo a arbustivo. Os capítulos, dispostos em corimbos terminais, têm invólucro globoso, hemisférico ou campanulado, com brácteas involucrais em 2-4 séries e receptáculo paleáceo nas plantas femininas, desnudo nas masculinas. As flores dos capítulos femininos são isomorfas, de corola carnosa e ápice breve-ligulado. As flores dos capítulos masculinos são dimorfas; as marginais, femininas ou neutras, possuem corola ligulada, ao passo que as flores masculinas do disco têm corola tubulosa de ápice dilatado, 5-lobado. O gênero inclui três espécies com distribuição geográfica limitada ao sul do Brasil (estados do Rio Grande do Sul e Santa Catarina), Uruguai e centro da Argentina (províncias de Córdoba, San Luis, Santiago del Estero e La Rioja).

Heterothalamus alienus é um arbusto de 1-5 m de altura, provido de folhas lineares, alternas, sésseis, uninérvias, glanduloso-pontuadas, com margens íntegras e ápice agudo, e de flores dispostas em corimbos

1. Bióloga, Doutoranda pelo Programa de Pós-Graduação em Engenharia Florestal, Centro de Ciências Rurais, Universidade Federal de Santa Maria, CEP 97105-900, Santa Maria (RS). anabela.biol@bol.com.br

2. Biólogo, Doutorando pelo Programa de Pós-Graduação em Engenharia Florestal, Centro de Ciências Rurais, Universidade Federal de Santa Maria, CEP 97105-900, Santa Maria (RS). deble.biol@bol.com.br

3. Engenheiro Florestal, Dr., Professor Titular do Departamento de Ciências Florestais, Centro de Ciências Rurais, Universidade Federal de Santa Maria, CEP 97105-900, Santa Maria (RS). marchiori@ccr.ufsm.br

4. Engenheiro Florestal, Doutorando pelo Programa de Pós-Graduação em Engenharia Florestal, Centro de Ciências Rurais, Universidade Federal de Santa Maria, CEP 97105-900, Santa Maria (RS).

Recebido para publicação em 1/06/2004 e aceito em 28/03/2005. 
terminais, composto de (1) 4-12 capítulos. O invólucro feminino, globoso (7-11 mm) e com brácteas involucrais 3-4-seriadas, compreende de 150-250 flores de corola carnosa e ápice breve-ligulado, com pápus curto, caduco, e páleas de 3-4 mm de comprimento, cimbiformes e de ápice triangular a obtuso. O invólucro masculino, campanulado e de 5-9 mm de diâmetro, apresenta brácteas involucrais 2-3-seriadas e cerca de cem flores dimorfas; as marginais, 1-2 seriadas, são liguladas e com corola de 2-2,5 mm de comprimento; as flores multisseriadas do disco masculinas e com 2,5-3 mm de comprimento, apresentam corola tubulosa de ápice dilatado, 5-lobado, e pápus de poucas cerdas caducas. O aquênio, 5-costado, é cônico e curvo, medindo 1,5-2 mm de comprimento. A planta, que floresce em outubro-novembro, e fevereiro-março, ocorre naturalmente tanto em Santa Catarina como no Rio Grande do Sul, habitando na Serra do Sudeste, na Campanha e na Serra Geral, em altitudes de 100 a mais de $1000 \mathrm{~m}$. Ocorre geralmente solos rasos e pedregosos, em barrancos e beira de estradas. Também é citado para o Uruguai (Departamentos de Canelones, Florida, Lavalleja, Maldonado e Rocha) e centro da Argentina (províncias de Córdoba, San Luis, Santiago del Estero e La Rioja). Nos países de língua castelhana, a espécie é conhecida como "romerillo" ou "romerillo-del-campo" e, no Brasil, como "alecrim ou "alecrim-do-campo".

Heterothalamus rupestris foi descrita recentemente e sua identidade era confundida com Heterothalamus alienus, da qual difere pelo menor porte, pelas folhas mais longas e dentadas na parte superior, pela inflorescência com menor número de capítulos, pelos pedúnculos mais curtos e pelas páleas menores, oblanceoladas (Deble, Oliveira \& Marchiori, 2003). Sua fenologia também difere, notavelmente, de Heterothalamus alienus, por ter sua principal floração entre o final do outono e início do inverno. Conhecido localmente pelos nomes de "alecrim-da-pedra”, "alecrim-rasteiro" ou "alecrim-do-inverno", Heterothalamus rupestris tem distribuição geográfica restrita à Serra do Sudeste do Rio Grande do Sul, em especial na região compreendida entre Bagé e Caçapava do Sul. Embora mais rara, também ocorre em Arroio dos Ratos, Encruzilhada do Sul, Santana da Boa Vista, Canguçu e Guaíba, de acordo com registros de herbários. A espécie habita afloramentos rochosos úmidos nas proximidades de matas e cursos d'água, por vezes em simpatria com Heterothalamus alienus e Heterothalamus psiadioides.

O xilema secundário do gênero Heterothalamus era desconhecido até o momento, o que pode ser explicado pelo porte reduzido de suas espécies e conseqüente falta de interesse econômico pelo lenho.

O presente trabalho visa à descrição anatômica da madeira de Heterothalamus alienus e Heterothalamus rupestris, à sua identificação pela estrutura microscópica do lenho e sua comparação com referências da literatura para a família Asteraceae e tribo Astereae.

\section{REVISÃO DE LITERATURA}

A estrutura anatômica da madeira na família Asteraceae caracteriza-se por apresentar anéis de crescimento pouco evidentes, porosidade difusa ou semidifusa e vasos tipicamente pequenos, ocasionalmente de tamanho médio, com placas de perfuração simples, mais raramente escalariforme-irregulares ou reticuladas. Os vasos, providos de pontoações intervasculares alternas, diminutas até moderadamente grandes, reúnem-se em agrupamentos diagonais e racemiformes irregulares, compondo, por vezes, um nítido padrão dendrítico. O parênquima axial, tipicamente paratraqueal e seriado, pode ser estratificado ou composto de células fusiformes (Metcalfe e Chalk, 1972; Record e Hess, 1949).

Os raios, tipicamente com 4-10 células de largura, e poucos unisseriados de baixa altura, são em poucas espécies exclusivamente unisseriados e, por vezes, estratificados; os multisseriados são compostos por uma mistura irregular de células eretas e procumbentes. As fibras pequenas e com pontoações simples, ocasionalmente septadas, variam de comprimento médio até muito curtas. Tilos e traqueídeos vasicêntricos são pouco freqüentes bem como a presença de canais intercelulares em raios. A presença de cristais não é reportada para a família (Metcalfe e Chalk, 1972; Record e Hess, 1949).

As características anatômicas da tribo Astereae foram investigadas, por Carlquist (1960), com base em espécies dos gêneros Baccharis, Haplopappus, Lepidospartum, Olearia e Psiadia. Para o autor, essa tribo é a mais evoluída da família quanto à anatomia da madeira, pois suas espécies reúnem características altamente especializadas. Os pequenos elementos vasculares referidos na literatura, todavia, podem relacionar-se tanto à elevada posição filogenética da tribo, como a uma especialização acelerada, por causa do hábitat geralmente seco, habitado, costumeiramente, por este grupo de plantas (Carlquist, 1960). 


\section{MATERIAL E MÉTODOS}

As amostras de madeira foram coletadas na região da Serra do Sudeste, no Rio Grande do Sul, entre os municípios de Caçapava do Sul e Santana da Boa Vista. Para o estudo anatômico, foram selecionados três indivíduos adultos de cada uma das espécies, tendo sido coletado de cada indivíduo um segmento do tronco com cerca de $50 \mathrm{~cm}$ de comprimento. De cada planta coletada, foram também preparadas exsicatas, com vistas à incorporação aos herbários CNPO, da Embrapa Pecuária Sul (Bagé, RS), e HDCF, da Universidade Federal de Santa Maria, RS.

De cada amostra de madeira foram preparados três corpos de prova, tomados em região de alburno e orientados para a obtenção de cortes anatômicos nos planos transversal, longitudinal radial e longitudinal tangencial.

A microtomia, realizada no Laboratório de Anatomia da Madeira da Universidade Federal do Paraná, seguiu a técnica tradicionalmente adotada na instituição. Os corpos de prova foram amolecidos por fervura em água e cortados em micrótomo de deslizamento, com espessura nominal de 18 micrômetros. Foi usada tripla coloração, com acridina-vermelha, crisoidina e azul-de-astra (Dujardin, 1964), desidratação em série alcoólica e montagem de lâminas permanentes, com "Entellan".

Para a confecção de lâminas de células lenhosas isoladas, adotou-se a maceração de palitos de madeira pelo método de Jeffrey (Freund, 1970). Usou-se safranina, para a coloração da pasta resultante, e o mesmo meio de montagem anteriormente referido para a montagem de lâminas permanentes.

A terminologia, número de medições e descrição da estrutura anatômica seguiram as recomendações da COPANT (1973). Para a determinação da percentagem dos diferentes tipos celulares, seguiu-se a metodologia recomendada por Marchiori (1980). As medições foram realizadas em microscópico Carl Zeiss no Laboratório de Anatomia da Madeira da Universidade Federal de Santa Maria. As fotomicrografias foram realizadas no Laboratório de Anatomia da Madeira da Universidade Federal do Paraná.

A análise quantitativa das características anatômicas seguiu a metodologia tradicional em anatomia da madeira (Marchiori e Brum, 1997), tendo sido obtidos os valores mínimos, médios, máximos e desvio-padrão, de cada um dos caracteres anatômicos, mediante programas de computador (STATGRAPHICS); os referidos valores quantitativos são apresentados nas Tabelas 1 e 2.

TABELA 1: Dados quantitativos do xilema de Heterothalamus alienus (Sprengel) O. Kuntze. TABLE 1: Quantitative date of the xylem Heterothalamus alienus (Sprengel) O. Kuntze.

\begin{tabular}{l|r|r|r|r|c}
\hline Características & $\mathrm{n}$ & $\mathrm{m}$ mín. & média & máx. & cV\% \\
\hline 1. Fração de Poros $(\%)$ & 1800 & 10,0 & 19,0 & 26,0 & 26,3 \\
2. Freqüência de Poros (poros $\left./ \mathrm{mm}^{2}\right)$ & 1800 & 424,0 & 478,3 & 582,0 & 11,6 \\
3. $\varnothing$ poros $(\mu \mathrm{m})$ & 90 & 15,0 & 35,3 & 60,0 & 26,6 \\
4. C. elementos vasculares $(\mu \mathrm{m})$ & 90 & 80,0 & 154,5 & 210,0 & 14,2 \\
5. C de apêndices $(\mu \mathrm{m})$ & 90 & 5,0 & 11,2 & 25,0 & 44,6 \\
6. $\varnothing$ lúmen de vasos $(\mu \mathrm{m})$ & 90 & 12,5 & 31,6 & 55,0 & 29,7 \\
7. E. da parede dos vasos $(\mu \mathrm{m})$ & 90 & 0,62 & 1,7 & 3,75 & 29,4 \\
8. $\varnothing$ das pontuações $(\mu \mathrm{m})$ & 90 & 4,1 & 5,7 & 7,21 & 12,3 \\
9. F. parênquima axial $(\%)$ & 1800 & 16,0 & 25,8 & 36,0 & 19,8 \\
10. H. séries parênquima axial $(\mu \mathrm{m})$ & 90 & 55,0 & 165,0 & 320,0 & 21,3 \\
11. H. séries parênquima axial $($ céls.) & 90 & 1,0 & 1,9 & 4,0 & 26,3 \\
12. H. células fusiformes $(\mu \mathrm{m})$ & 90 & 50,0 & 91,5 & 190,0 & 31,5 \\
13. L. células fusiformes $(\mu \mathrm{m})$ & 90 & 10,0 & 14,9 & 22,0 & 16,8 \\
14. F. tecido radial $(\%)$ & 1800 & 6,0 & 11,0 & 18,0 & 33,6 \\
15. Freqüência de raios $(\mathrm{raios} / \mathrm{mm})$ & 90 & 3,0 & 5,0 & 7,0 & 22,0 \\
16. F. raios unisseriados $(\%)$ & 1800 & 11,0 & 23,4 & 42,0 & 47,0 \\
17. H. raios unisseriados $(\mu \mathrm{m})$ & 90 & 20,0 & 80,7 & 160,0 & 38,2 \\
\hline
\end{tabular}


TABELA 1: Continuação ...

TABLE 1: Continued ...

\begin{tabular}{l|r|r|r|r|r}
\hline Características & n & mín. & média & máx. & cv\% \\
\hline 18. H. raios unisseriados (céls.) & 90 & 1,0 & 3,5 & 8,0 & 40,0 \\
19. L. raios unisseriados $(\mu \mathrm{m})$ & 90 & 10,0 & 19,3 & 27,5 & 19,2 \\
20. H. raios multisseriados $(\mu \mathrm{m})$ & 90 & 60,0 & 241,6 & 720,0 & 46,6 \\
21. H. raios multisseriados (céls.) & 90 & 3,0 & 12,7 & 35,0 & 45,7 \\
22. L. raios multisseriados $(\mu \mathrm{m})$ & 90 & 10,0 & 36,0 & 55,0 & 22,8 \\
23. L. raios multisseriados (céls.) & 90 & 2,0 & 2,7 & 4,0 & 22,2 \\
24. F. raios 2-seriados $(\%)$ & 1800 & 26,0 & 36,1 & 50,0 & 22,2 \\
25. F. raios 3-seriados $(\%)$ & 1800 & 18,0 & 36,3 & 48,0 & 24,0 \\
26. F. raios 4-seriados $(\%)$ & 1800 & 2,0 & 4,5 & 11,0 & 62,2 \\
27. F. fibras $(\%)$ & 1800 & 30,0 & 44,0 & 53,0 & 12,5 \\
28. C. fibras $(\mu \mathrm{m})$ & 90 & 430,0 & 572,3 & 800,0 & 13,0 \\
29. $\varnothing$ lúmen de fibras $(\mu \mathrm{m})$ & 90 & 5,0 & 7,4 & 11,25 & 18,9 \\
30. E. parede das fibras $(\mu \mathrm{m})$ & 90 & 1,2 & 2,5 & 3,75 & 20,0 \\
31. $\varnothing$ fibras & 90 & 10,0 & 12,4 & 17,5 & 13,7 \\
\hline
\end{tabular}

Em que: $\mathrm{n}$ = número de medições; mín. = valor mínimo; máx. = valor máximo; $\mathrm{cv} \%$ = coeficiente de variação; $\mathrm{F}$. = fração; C. = comprimento; H. = altura; L. = largura; E. = espessura, $\varnothing=$ diâmetro.

TABELA 2: Dados quantitativos do xilema de Heterothalamus rupestris Deble, Oliveira e Marchiori.

TABLE 2: Quantitative date of the xylem Heterothalamus rupestris Deble, Oliveira e Marchiori.

\begin{tabular}{|c|c|c|c|c|c|}
\hline Características & $\mathrm{n}$ & mín. & média & máx. & $\mathrm{CV} \%$ \\
\hline 1. Fração de Poros (\%) & 1800 & 12,0 & 15,6 & 25,0 & 19,9 \\
\hline 2. Freqüência de Poros (poros $/ \mathrm{mm}^{2}$ ) & 1800 & 248,0 & 363,3 & 432,0 & 17,8 \\
\hline 3. $\varnothing$ poros $(\mu \mathrm{m})$ & 90 & 17,5 & 31,6 & 65,0 & 25,9 \\
\hline 4. C. elementos vasculares $(\mu \mathrm{m})$ & 90 & 80,0 & 162,1 & 245,0 & 19,9 \\
\hline 5. C de apêndices $(\mu \mathrm{m})$ & 90 & 5,0 & 15,5 & 42,5 & 56,1 \\
\hline 6. $\varnothing$ lúmen de vasos $(\mu \mathrm{m})$ & 90 & 10,0 & 25,9 & 58,7 & 30,1 \\
\hline 7. E. da parede dos vasos $(\mu \mathrm{m})$ & 90 & 1,2 & 2,8 & 6,2 & 25,0 \\
\hline 8. $\varnothing$ das pontuações $(\mu \mathrm{m})$ & 90 & 4,1 & 5,0 & 6,1 & 10,0 \\
\hline 9. F. parênquima axial (\%) & 1800 & 6,0 & 14,8 & 22,0 & 31,8 \\
\hline 10. H. séries parênquima axial $(\mu \mathrm{m})$ & 90 & 80,0 & 155,5 & 220,0 & 19,7 \\
\hline 11. H. séries parênquima axial (céls.) & 90 & 1,0 & 1,9 & 2,0 & 10,5 \\
\hline 12. H. células fusiformes $(\mu \mathrm{m})$ & 90 & 50,0 & 80,2 & 120,0 & 18,1 \\
\hline 13. L. células fusiformes $(\mu \mathrm{m})$ & 90 & 6,2 & 10,4 & 12,5 & 13,5 \\
\hline 14. F. tecido radial (\%) & 1800 & 9,0 & 14,6 & 21,0 & 22,6 \\
\hline 15. Freqüência de raios (raios/mm) & 90 & 5,0 & 8,0 & 12,0 & 20,0 \\
\hline 16. F. raios unisseriados (\%) & 1800 & 26,0 & 35,5 & 42,0 & 14,9 \\
\hline 17. H. raios unisseriados $(\mu \mathrm{m})$ & 90 & 40,0 & 161,0 & 760,0 & 74,8 \\
\hline 18. H. raios unisseriados (céls.) & 90 & 1,0 & 6,2 & 36,0 & 85,5 \\
\hline 19. L. raios unisseriados $(\mu \mathrm{m})$ & 90 & 6,2 & 18,5 & 35,0 & 27,2 \\
\hline 20. H. raios multisseriados $(\mu \mathrm{m})$ & 90 & 120,0 & 329,7 & 810,0 & 44,1 \\
\hline 21. H. raios multisseriados (céls.) & 90 & 4,0 & 13,6 & 36,0 & 47,1 \\
\hline 22. L. raios multisseriados $(\mu \mathrm{m})$ & 90 & 15,0 & 34,7 & 60,0 & 26,2 \\
\hline 23. L. raios multisseriados (céls.) & 90 & 2,0 & 2,5 & 4,0 & 24,0 \\
\hline 24. F. raios 2-seriados (\%) & 1800 & 34,0 & 40,9 & 48,0 & 9,54 \\
\hline
\end{tabular}


TABELA 2: Continuação ...

TABLE 2: Continued ...

\begin{tabular}{l|r|r|r|r|c}
\hline Características & $\mathrm{n}$ & mín. & média & máx. & cv\% \\
\hline 25. F. raios 3-seriados (\%) & 1800 & 11,0 & 21,1 & 35,0 & 32,2 \\
26. F. raios 4-seriados (\%) & 1800 & 1,0 & 2,2 & 4,0 & 40,9 \\
27. F. fibras (\%) & 1800 & 44,0 & 54,7 & 64,0 & 10,8 \\
28. C. fibras $(\mu \mathrm{m})$ & 90 & 350,0 & 463,3 & 600,0 & 11,9 \\
29. $\varnothing$ lúmen de fibras $(\mu \mathrm{m})$ & 90 & 3,7 & 6,1 & 10,0 & 23,0 \\
30. E. parede das fibras $(\mu \mathrm{m})$ & 90 & 1,2 & 2,8 & 5,6 & 28,6 \\
31. $\varnothing$ fibras & 90 & 7,5 & 11,9 & 17,5 & 19,3 \\
\hline
\end{tabular}

Em que: $\mathrm{n}$ = número de medições; mín. = valor mínimo; máx. = valor máximo; cv\%: coeficiente de variação; $\mathrm{F}$. = fração; C. = comprimento; H. = altura; L. = largura; E. = espessura, $\varnothing=$ diâmetro.

\section{DESCRIÇÃO MICROSCÓPICA DA MADEIRA DE Heterothalamus alienus (Sprengel) O. Kuntze} (Figura 1)

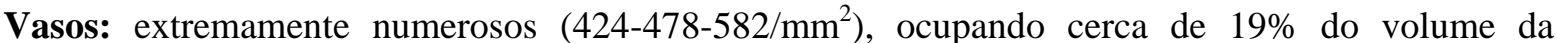
madeira. Vasos em distribuição difusa não-uniforme, formando agrupamentos diagonais e racemiformes (dendrítico, sensu IAWA, 1989); vasos solitários, raros. Vasos extremamente pequenos até pequenos, (1535-60 $\mu \mathrm{m})$, de seção poligonal. Elementos vasculares muito curtos $(80-154-210 \mu \mathrm{m})$, com placas de perfuração simples, e espessamentos espiralados na parede, apêndices ausentes, ou então curtos (511-25 $\mu \mathrm{m}$ ), em uma ou em ambas as extremidades. Vasos com abundante conteúdo (goma ou resina), no cerne; tilos, ausentes. Pontoações intervasculares alternas, de forma oval ou poligonal quando aproximadas, pequenas $(4-5,7-7 \mu \mathrm{m})$ e com abertura horizontal, lenticular, inclusa.

Parênquima axial: abundante, em disposição paratraqueal vasicêntrica e ocupando cerca de $26 \%$ da seção transversal da madeira. Células parenquimáticas fusiformes de 50-91-190 $\mu \mathrm{m}$ de altura por 10-15-22 $\mu \mathrm{m}$ de diâmetro, em arranjo estratificado. Séries parenquimáticas verticais também estratificadas, de 55-165-320 $\mu$ m de altura, com 1 ou 2, raramente 3 ou 4 células por série.

Raios: tecido radial heterogêneo, ocupando cerca de $12 \%$ do volume da madeira e com freqüência de 3-5-7 raios/mm. Raios unisseriados abundantes (23\% do total), muito baixos (20-80-160 $\mu \mathrm{m})$, de extremamente finos até muito finos (10-19-27 $\mu \mathrm{m})$ e com 1-4-8 células de altura. Raios multisseriados, em sua maioria bisseriados (36,1\% do total) e trisseriados (36,3\%), raro tetrasseriados (4,5\% do total); de muito baixos até medianos (60-241,6-720 $\mu \mathrm{m})$, com 3-13-35 células de altura, e de extremamente finos a estreitos (10-36-55 $\mu \mathrm{m})$. Tecido radial heterogêneo do Tipo III, reunindo células procumbentes e quadradas; estas, confinadas às margens dos raios. Células cristalíferas, envolventes, eretas, esclerosadas, latericuliformes, mucilaginosas e oleíferas, ausentes.

Fibras: ocupando cerca de $44 \%$ do volume da madeira. Fibras libriformes, não septadas e providas de pontuações simples, diminutas. Variam de extremamente curtas até muito curtas (430-572-800 $\mu \mathrm{m})$, são estreitas $(10-12-17 \mu \mathrm{m})$ e de paredes espessas (1,2-2,5-3,7 $\mu \mathrm{m})$. Fibras gelatinosas, presentes.

Outros caracteres: canais secretores, tubos lactíferos e taniníferos bem como liber incluso ausentes. Estratificação parcial, de vasos e parênquima axial. Anéis de crescimento, indistintos. 

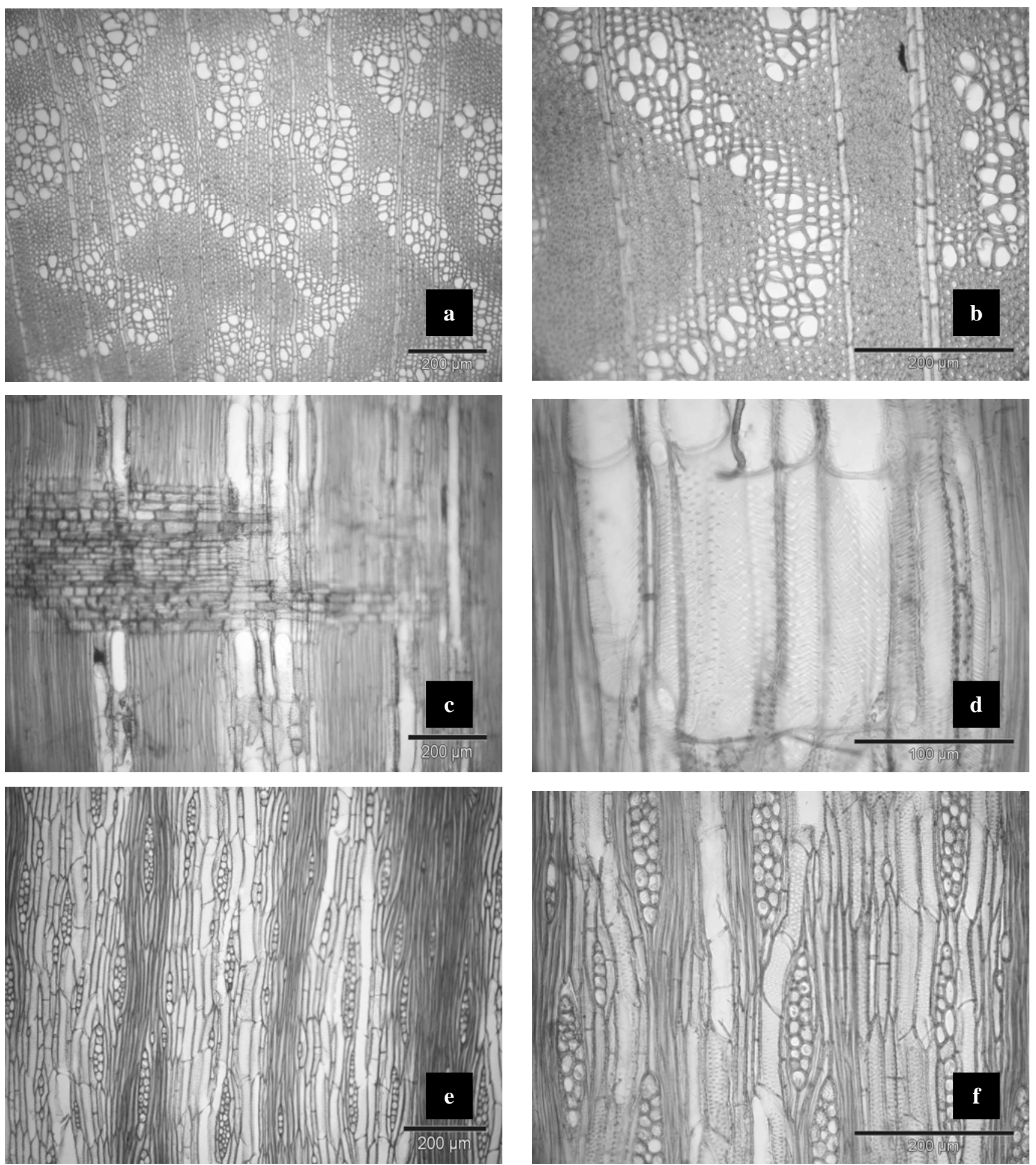

FIGURA 1: Aspectos anatômicos da madeira de Heterothalamus alienus. a) Seção transversal mostrando poros racemiformes em arranjo dendrítico. b) Seção transversal mostrando o parênquima axial em disposição paratraqueal vasicêntrica. c) Seção longitudinal radial destacando os raios heterogêneos. d) Seção longitudinal radial mostrando espessamentos espiralados nos vasos e pontoações alternas. e) e f). Seção longitudinal tangencial mostrando parênquima axial estratificado e raios unisseriados e multisseriados.

FIGURE 1: Wood anatomy aspects of Heterothalamus alienus. a) Transection, showing pore clusters in dendritic pattern. b) Transection, showing the vasicentric paratracheal parenchyma. c) The heterogeneous ray, in radial section. d) Radial section, showing spiral thickenings in vessels with alternate pitting. e) and f). Two tangential sections, showing uniseriate and multiseriate rays, and the storied parenchyma. 
DESCRIÇÃO MICROSCÓPICA DA MADEIRA DE Heterothalamus rupestris Deble, Oliveira et Marchiori (Figura 2)

Vasos: extremamente numerosos $\left(248-363,3-432 / \mathrm{mm}^{2}\right)$ ocupando cerca de $16 \%$ do volume total da madeira. Vasos em distribuição difusa, não-uniforme e dispostos em agrupamentos diagonais e racemiformes (dendrítico, sensu IAWA, 1989); vasos solitários, raros. Vasos extremamente pequenos até pequenos (17-31$65 \mu \mathrm{m})$, de seção poligonal. Elementos vasculares muito curtos (80-162-245 $\mu \mathrm{m})$, com placas de perfuração simples, desprovidos de espessamentos espiralados na parede e com apêndices ausentes, ou então curtos (515-42 $\mu \mathrm{m}$ ), em uma ou em ambas as extremidades. Pontoações intervasculares alternas, pequenas (4-5,5-6 $\mu \mathrm{m})$ e de forma oval até poligonal, com abertura lenticular, horizontal, inclusa. Vasos com abundante conteúdo (goma ou resina) no cerne; tilos ausentes.

Parênquima axial: pouco abundante ocupando cerca de 15\% da seção transversal da madeira. Células parenquimáticas em disposição paratraqueal vasicêntrica até unilateral, sendo, todavia, freqüente 0 contato com fibras. Células parenquimáticas fusiformes de 50-80,2-120 $\mu \mathrm{m}$ de altura por 6,2-10,4-12,5 $\mu \mathrm{m}$ de diâmetro. Séries parenquimáticas verticais com 80-155-220 $\mu \mathrm{m}$ de altura, e 2 células por série.

Raios: tecido radial heterogêneo ocupando cerca de 15\%do volume da madeira e com freqüência de 5-8-12 raios/mm. Raios unisseriados abundantes (35\% do total), muito baixos até medianos (40161-760 $\mu \mathrm{m})$, de extremamente finos a finos $(6-18-35 \mu \mathrm{m})$ e com 1-6-36 células de altura. Raios multisseriados, em sua maioria bisseriados ( $40,9 \%$ do total), menos comumente trisseriados ( $21,1 \%$ do total), raro tetrasseriados (2,2\% do total); variam de muito baixos a altos (120-329,7-810 $\mu \mathrm{m})$, de extremamente finos a estreitos (15-34-60 $\mu \mathrm{m})$, com 4-14-36 células de altura. Tecido radial heterogêneo do Tipo III, reunindo células curtamente procumbentes e células quadradas, estas na margem dos raios. Células cristalíferas, envolventes, eretas, esclerosadas, latericuliformes, mucilaginosas e oleíferas, ausentes.

Fibras: ocupando cerca de 55\% do volume da madeira. São fibras libriformes, não-septadas, e providas de pontoações simples, diminutas. As fibras são extremamente curtas até muito curtas (350-463-600 $\mu \mathrm{m})$, estreitas $(7-12-17 \mu \mathrm{m})$ e de paredes espessas $(1,2-2,8-5,6 \mu \mathrm{m})$. Fibras gelatinosas, presentes.

Outros caracteres: canais secretores, tubos lactíferos e taniníferos, liber incluso e estratificação, ausentes. Anéis de crescimento, indistintos. 

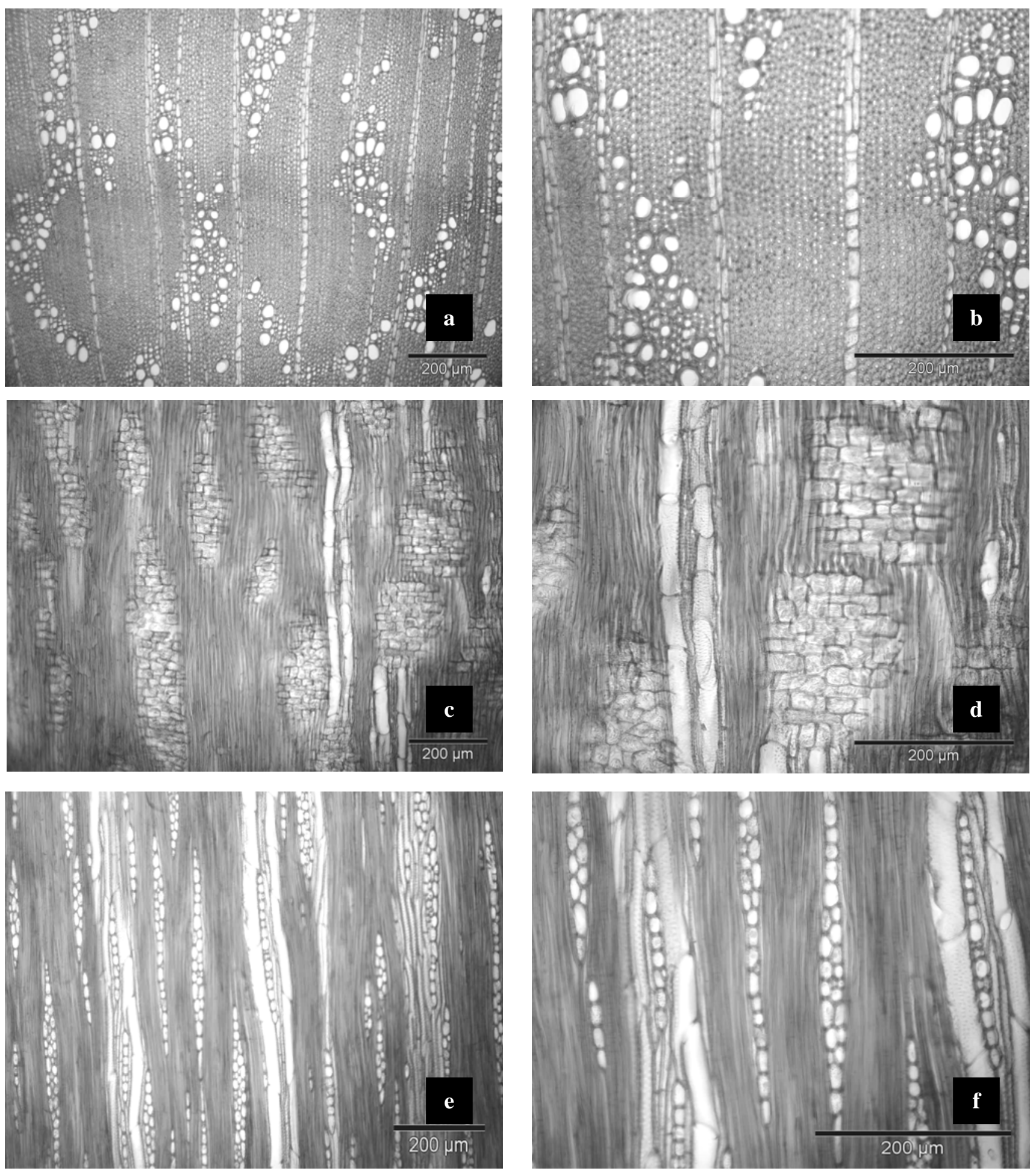

FIGURA 2: Aspectos anatômicos da madeira de Heterothalamus rupestris. a) Seção transversal mostrando poros racemiformes em arranjo dendrítico. b) Seção transversal mostrando o parênquima axial em disposição paratraqueal vasicêntrica até unilateral. c) Seção longitudinal radial destacando raios heterogêneos. d) Seção longitudinal radial mostrando vasos sem espessamentos espiralados e pontoações alternas. e) e f) Seção longitudinal tangencial, com parênquima axial estratificado e raios uni e multisseriados.

FIGURE 2: Wood anatomy aspects of Heterothalamus rupestris. a) Transection, showing pore clusters in dendritic pattern. b) Transection, showing the axial parenchyma, in vasicentric paratracheal to unilateral pattern. c) Heterogeneous rays, in radial section. d) Radial section, showing vessels with spiral thickenings and alternate pitting. e) and f) Tangential sections, showing the storied parenchyma and uniseriate and multiseriate rays. 


\section{DISCUSSÃO}

As principais características da estrutura microscópica das madeiras de Heterothalamus alienus e Heterothalamus rupestris (Figs. 3 e 4) correspondem ao descrito na literatura anatômica para a família Asteraceae, por Metcalfe e Chalk (1972) e Record e Hess (1949). É o caso da ocorrência de porosidade difusa, de vasos com placas de perfuração simples, do parênquima paratraqueal e das pontoações alternas, diminutas. A presença de espessamentos espiralados e de estratificação no parênquima axial em uma das espécies estudadas (Heterothalamus alienus) também concorda com as possibilidades estruturais referidas, pelos autores acima mencionados, para as Asteraceae.

O agrupamento de vasos em múltiplos diagonais e racemiformes (arranjo dendrítico), o parênquima paratraqueal vasicêntrico abundante até escasso, o tecido radial heterogêneo do tipo III, reunindo células procumbentes e quadradas bem como as fibras libriformes - aspectos anatômicos observados nas espécies em estudo -, foram também referidos por Carlquist (1960) para a tribo Astereae.

Record e Hess (1949) chamam atenção para a presença freqüente de porosidade difusa, de anéis de crescimento estreitos, da abundância de vasos e parênquima, assim como de elementos vasculares curtos e de pequeno diâmetro - aspectos anatômicos observados em ambas as espécies estudadas - nas madeiras de arbustos esclerófilos e de deserto. Para a mesma situação ecológica, os autores ainda destacam a ocorrência de elementos vasculares curtos e de diâmetro pequeno, constatados em ambas as madeiras estudadas bem como da presença de espessamentos espiralados na parede, aspecto reportado apenas para Heterothalamus alienus. A estrutura anatômica, desse modo, atesta um caráter mais acentuadamente xeromórfico à madeira de Heterothalamus alienus, concordando com distribuição geográfica da espécie que habita sabidamente ambientes mais secos e sítios mais elevados do que Heterothalamus rupestris.

Em Heterothalamus alienus, observou-se a presença de estratificação no parênquima axial. Esse aspecto sabidamente evoluído (Metcalfe e Chalk, 1972; Record e Hess, 1949) indicam maior especialização anatômica para a referida espécie, comparada a Heterothalamus rupestris.

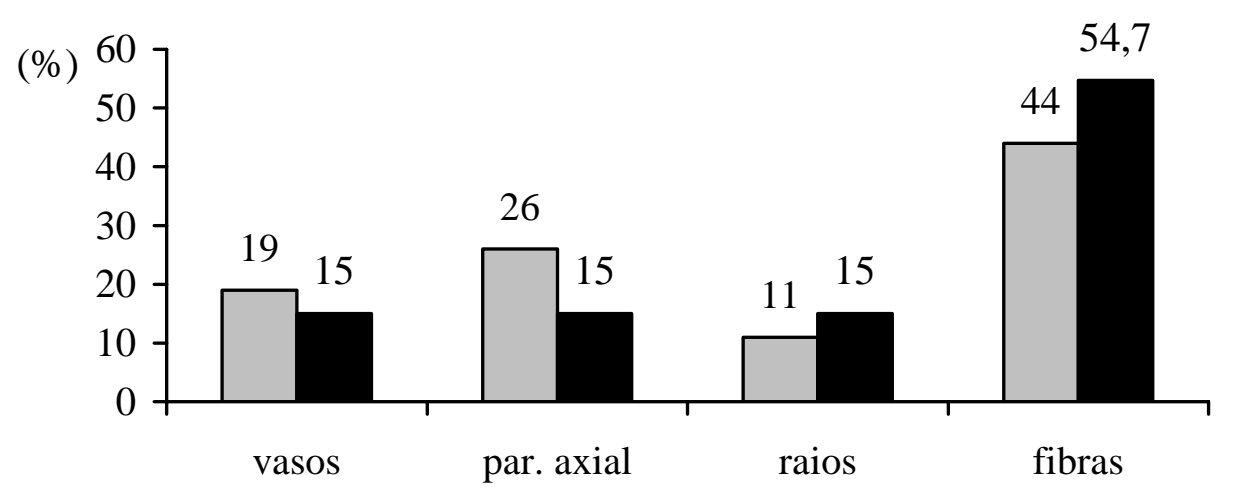

$\square$ Heterothalamus alienus $\mathbf{\square}$ Heterothalamus rupestris

FIGURA 3: Percentagem dos tipos celulares constituintes da madeira em Heterothalamus alienus e $H$. rupestris.

FIGURE 3: Percentage of cell types in the wood Heterothalamus alienus and Heterothalamus rupestris. 

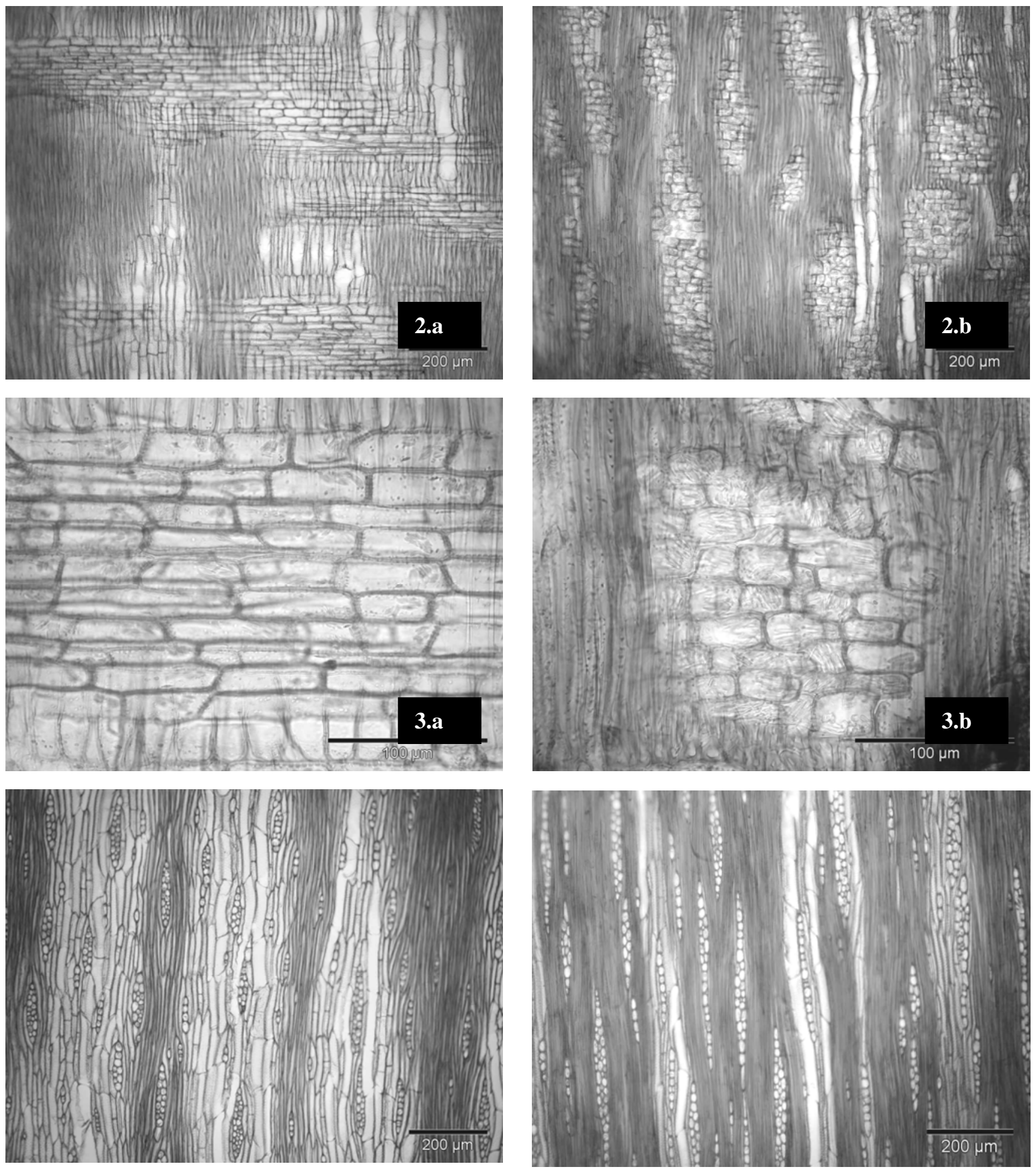

FIGURA 4: Comparação entre aspectos anatômicos da madeira de Heterothalamus alienus (a) e Heterothalamus rupestris (b). 1. Raios heterogêneos em seções longitudinais radiais. 2 Composição das células radiais (quadradas ou procumbentes), em seções longitudinais radiais. 3. Seções longitudinais tangenciais, salientando as diferenças quanto à estratificação e largura dos raios em número de células.

FIGURE 4: Wood anatomy comparison between Heterothalamus alienus (a) and Heterothalamus rupestris (b). 1. Heterogeneous rays, in radial sections. 2. Cell ray types (upright versus procument), in radial sections. 3. Differences in tangential sections, with respect to the number of cells in ray width and storied (or no storied) structure. 
Em Heterothalamus rupestris não foram observados espessamentos espiralados, caráter que pode estar relacionado à posição filogenética da espécie, dentro do gênero. Para Carlquist (1960), os espessamentos espiralados, observados em Astereae, são de ocorrência excepcional na família Asteraceae. Pelos casos aparentemente transitivos e por afinidade taxonômica interna a tipos mais elaborados, o autor sugere que, entre as espécies de um mesmo gênero, o caráter representa uma especialização anatômica de uma condição não-espiralada para a espiralada. Com base neste caráter anatômico, Heterothalamus alienus também deve ser interpretado como evoluído, em relação a Heterothalamus rupestris.

\section{CONCLUSÕES}

O estudo anatômico das madeiras de Heterothalamus alienus e Heterothalamus rupestris permite a formulação das seguintes conclusões:

- Tanto Heterothalamus alienus como Heterothalamus rupestris apresentam o conjunto de características anatômicas referido na literatura para a família Asteraceae e tribo Astereae.

- A identificação das duas espécies pode ser realizada pela da anatomia da madeira.

- Heterothalamus alienus distingue-se pela abundância de parênquima axial que é estratificado e em arranjo vasicêntrico pelos espessamentos espiralados nos vasos e pela menor freqüência de raios (3-5-7/mm).

- Heterothalamus rupestris identifica-se pelo parênquima escasso, vasicêntrico até unilateral, pelos vasos desprovidos de espessamentos espiralados e pela maior freqüência de raios (5-8-12/mm).

\section{AGRADECIMENTOS}

Os autores agradecem à CAPES, pela concessão da bolsa e ao Curso de Pós-Graduação em Engenharia Florestal da UFSM.

\section{REFERÊNCIAS BIBLIOGRÁFICAS}

BARROSO, G. M. Sistemática de angiospermas do Brasil. Viçosa: Editora UFV, 1991. v.3.

CARLQUIST, S. Wood anatomy of Astereae (Compositae). Trop. Woods, v. 113, p.54-84, 1960.

COPANT. Comissão Panamericana de Normas Técnicas : descrição macroscópica, microscópica e geral da madeira - esquema I de recomendação. Colômbia, 1973. 19p. (COPANT 30).

DEBLE, L. P.; OLIVEIRA, A. S.; MARCHIORI, J. N. Heterothalamus rupestris, espécie nova de Asteraceae do Rio Grande do Sul. In: Ciência Florestal, Santa Maria, v. 13, n. 2, p. 1-5, 2003.

DUJARDIN, E. P. Eine neue holz-zellulosenfaerbung. Mikrokosmos, v. 53, p.94, 1964.

FREUND, H. Handbuch der Mikroskopie in der Technik. Frankfurt : Umschan Verlag, 1970. 379p.

IAWA. List of microscopic features for hardwood identification. IAWA Bullettin, Leiden, v. 10, n. 3, p. 219-332, 1989.

MARCHIORI, J. N. C. Estudo anatômico do xilema secundário de algumas espécies dos gêneros Acacia e Mimosa, nativas no Estado do Rio Grande do Sul. 1980. 186p. Dissertação (Mestrado em Engenharia Florestal) Universidade Federal do Paraná, Curitiba, 1980.

MARCHIORI, J. N. C. ; BRUM, E. T. Anatomia da madeira do guamirim-facho, Calyptranthes concina DC. Ciência Rural, Santa Maria, v. 27, n. 2, p. 217-222, 1997.

METCALFE, C. R.; CHALK, L. Anatomy of the dicotyledons. Oxford : Clarendon Press, 1972. v.2..

RECORD, S. J; HESS, R. W. Timbers of The New World. New Haven: Yale University Press, 1949. 640p. 